\title{
Effects of Pulsed Currents on Respiration and the Heart
}

\author{
W. R. LEE, S. ZOLEDZIOWSKI, and S TEMIYACHOL ${ }^{1}$ \\ From the Department of Occupational Health, University of Manchester, and the Department of \\ Electrical Engineering, University of Salford
}

The effects on the respiratory and circulatory systems of rabbits of pulsed currents from two sources have been studied. The sources were an industrial high voltage test-set (source A) and an automobile ignition system (source B).

When the fore-limb to fore-limb pathway was used, source A produced complete arrest of respiration at the highest output voltage, $5 \mathrm{kV}$ (corresponding to a current of $392 \mathrm{~mA}$ ), and at a pulse repetition rate of 30 per second. Progressive reduction of either of these factors resulted in progressively less interference with respiration. With the fore-limb to hind-limb pathway complete arrest of respiration occurred at an output voltage of $2 \mathrm{kV}$ (corresponding to a current of $140 \mathrm{~mA}$ ) and at a pulse repetition rate of 30 per second. Again progressive reduction of either current or pulse repetition rate resulted in progressively less interference with respiration, although at 30 per second even with the lowest voltage setting $(\mathrm{I} \mathrm{kV} ; 64 \mathrm{~mA})$ only diaphragmatic respiration occurred. Source B used on either pathway up to a pulse repetition rate of I6 per second did not cause complete arrest of respiration whether the current was taken straight from the ignition coil or off the distributor.

Neither source caused ventricular fibrillation either when delivering pulses at a preset rate or when the pulses were timed to coincide with successive $T$ waves of the E.C.G. In these experiments the trains of pulses falling on the $T$ waves lasted about ro seconds.

With both sources the current and voltage waveforms were similar and in phase. With source $A$ increase in current was directly related to increase in applied voltage. These findings suggest that under these experimental conditions, with minimum contact resistance, the animal impedance is resistive with no significant reactance.

The biological effects of mains frequency alternating currents have been studied for many years (Prevost and Battelli, 1899; Ferris, King, Spence, and Williams, 1936; Kouwenhoven, Chesnut, Knickerbocker, Milnor, and Sass, 1964) and evidence is accumulating that death is usually due to ventricular fibrillation in the common limb to limb shock at medium voltage (Lee, 1965a). It is possible that currents following these pathways may, in some instances, cause asphyxial death from tetanic contraction of the respiratory muscles (Lee, 1965b). Finally, death may result from arrest of respiration, particularly if the current passes through the respiratory centre (Machlachlan, 1930; Morikawa and Steichen, 1960), although this is an unusual current pathway in fatal accidents (Lee, 1965a).

Less is known about the effects of direct current,

'Present address: Metropolitan Electricity Authority, Bangkok, Thailand.

Received for publication November 17, 1966. but it is known that, in general, the effects of direct current are similar to those of alternating current, but at somewhat higher threshold values, on muscle (Dalziel, Ogden, and Abbott, 1943), on the heart (Ferris et al., 1936), and on respiration (Angelis, Lee, and Zoledziowski, 1965).

The biological effects of pulsed currents have received little attention, although, in industry, pulsed currents find a variety of applications. In different situations there will be different pulse shapes, pulse current and voltage amplitudes, and pulse repetition rates. Furthermore, such pulses are frequently generated as voltage pulses, whilst the effects of electric shock generally depend upon the current. Because the internal impedances of the circuits are frequently large, it is necessary to consider not the normal output values but the current output of the source when loaded during the shock.

This paper reports the results of experiments with 
some pulsed currents, together with a discussion of the results obtained in the light of physiological knowledge, thus making an initial contribution to the establishment of a more precise model. The current pathways selected were those noted above as the most common in electrical accidents, from an upper limb either to the opposite upper limb or to a lower limb.

\section{Experimental Method}

Two instruments were used to supply pulses. The first was an industrial 'insulation test-set' called source A, which on no-load produced voltage pulses up to $5 \mathrm{kV}$ with nominal settings of $1,2,3,4$, and $5 \mathrm{kV}$ peak. The internal impedance of the instrument was about $12 \mathrm{k} \Omega$. The repetition rates obtained from this source were varied from 3 to $30 \mathrm{c} / \mathrm{s}$.

The second source was an automobile ignition system (Lucas), here designated as source B. The output voltage, current, and waveshape of this source depend critically on the external loading.

Rabbits were used, as their hearts frequently defibrillate spontaneously and there is a body of knowledge of the effects of alternating and direct current on these animals (Lee and Zoledziowski, 1964; Angelis et al., 1965). Intravenous urethane (ethyl carbamate) was used as the anaesthetic. The experimental technique was closely similar to that employed by Angelis and his colleagues (1965), except that respiration was monitored using a respiratory transducer employing a modification of the system described by Green and Howell (1955) in which a small disc is placed in the airstream and connected to the anode of an RCA 5734 transducer valve. Changes in valve resistance were recorded by connecting the valve to a Wheatstone Bridge supplied from a stabilized rectified A.C. supply. The recording galvanometer (Honeywell, BB 30) and oscilloscope outputs were connected in the null branch of the bridge, which also contained high frequency filters (Fig. I). Inspiration produced an upward displacement of the tracing. The respiratory transducer was connected to a short glass tube inserted into the trachea, and respiration was recorded with a multi-channel ultra-violet light recorder (Honeywell, type 2500) and simultaneously displayed on an oscilloscope.

Blood pressure was recorded by connecting a catheter, inserted into a common carotid artery, to a Statham strain gauge. The output of the strain gauge was amplified with a Honeywell type 2585 blood pressure amplifier and simultaneously displayed on an oscilloscope and recorded on the multi-channel recorder with a Honeywell BB I30 galvanometer. The electrocardiogram was taken through a Honeywell type 258I E.C.G. amplifier and again simultaneously displayed on an oscilloscope and recorded with a Honeywell BB 250 galvanometer on the multi-channel recorder. The electrocardiograph was manually disconnected during the period of the shock in the experiments on respiration and therefore blood pressure readings alone gave some indication of cardiac activity.

To investigate the effects on the heart a different experimental circuit was required. Previous investigators have shown that ventricular fibrillation will occur only if the current is passed during the relative refractory period of the cardiac cycle (Ferris et al., 1936; Wégria and Wiggers, 1940).

Attempts to trigger the shock using a delay circuit initiated by the $R$ wave of the E.C.G. were not successful, because the switching surges produced when connecting and disconnecting the E.C.G. were larger than the $\mathbf{R}$ wave and induced transients in the circuit. The circuit shown in Fig. 2 was devised to investigate the effect of pulsed current on the heart, using the output from source $A$. The blood pressure pulse signal was amplified and employed as a tripping pulse for the delayed pulse generator (D.P.G.). The D.P.G. produced a $50 \mathrm{~V}$ rectangular pulse of variable duration at a variable preset time interval after the initial tripping blood pressure wave. The $50 \mathrm{~V}$ pulse operated a fast-acting relay which short-circuited the E.C.G. input terminals a-a and triggered source $A$ which was set at the maximum setting of $5 \mathrm{kV}$ at no load. This procedure allowed the shock pulses to be delivered in synchronism with each $\mathrm{T}$ wave of the cardiac cycle, or at any other selected point along the E.C.G. trace. At this stage no satisfactory E.C.G. recording could be obtained because of dis-

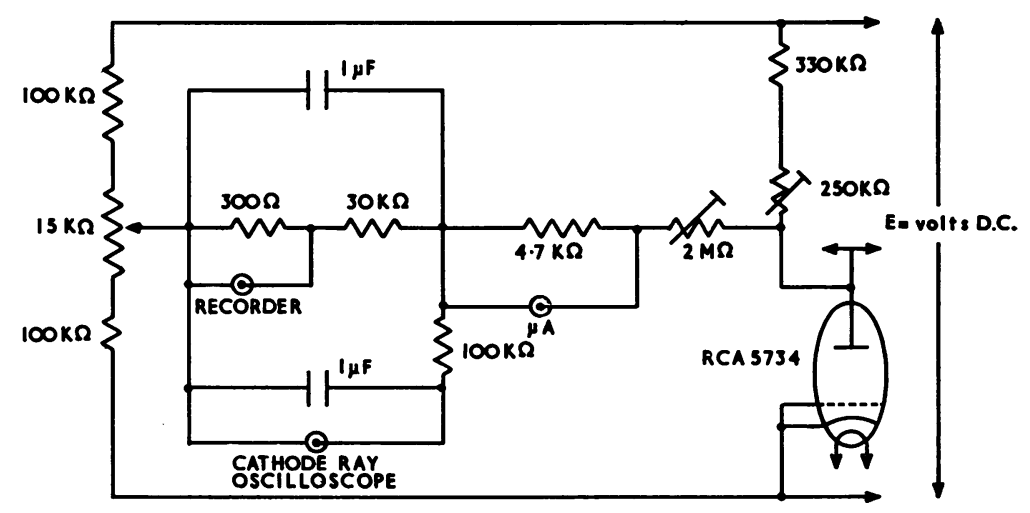

FIG. I. The respiratory transducer circuit. 




turbances produced by switching surges and by contact potentials from the animal and from the relay. The circuit elements shown in Fig. 2 were introduced to eliminate a great proportion of these disturbances while the two $3.5 \mathrm{~V}$ zener diodes $\mathrm{Z}$ eliminated low voltage mains frequency interference originating from source $A$.

Source B was used in the circuit of Figure 3. The ignition coil produces a voltage output when the primary low voltage circuit is opened, and also a second, but smaller voltage pulse when the circuit is closed. To protect the E.C.G. from these two voltages, the $50 \mathrm{~V}$ pulse-operating switch $S_{1}$, which short-circuits the E.C.G., has to be of longer duration than that applied to $S_{2}$, and $S_{1}$ has to close its contacts before switch $S_{2}$ operates. A I $\mu \mathrm{F}$ capacitor in the driving circuit of switch $S_{2}$ decreases the pulse width to a few milliseconds, after which switch $S_{2}$ closes. The associated rectifier cuts off the second pulse, which is passed through the capacitor as the $50 \mathrm{~V}$ pulse decreases to zero. This circuit delivered shocks to the animal only when switch
$\mathrm{S}_{3}$ was closed. Figure 4 indicates diagrammatically the switching sequence. The relays operating switches $S_{1}$ and $S_{2}$ were not identical, and $S_{1}$ operated some microseconds before switch $S_{2}$, as indicated in the Figure.

For clarity, the monitoring oscilloscopes, the respiration transducer, the respiration pump, and the recorder are not included in Figures 2 and 3.

The applied voltage and the current values of the pulse were measured by photography of displays on a double-beam oscilloscope screen. The details of the circuits will be described under each of the instruments used to supply pulses. Pulse repetition rate was checked by photographing such displays against a $50 \mathrm{c} / \mathrm{s}$ time marker.

\section{Results}

Effects on Respiration Each effect to be described was observed on about three or four different animals. 


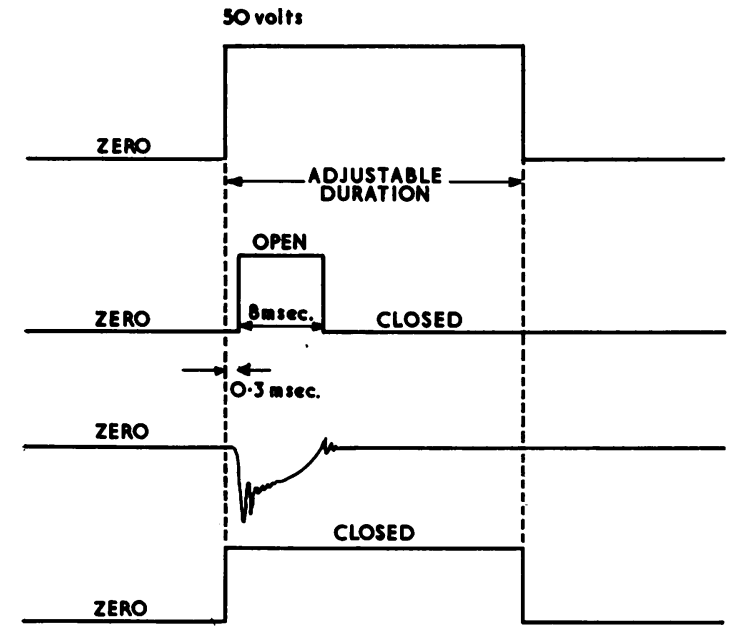

\section{Source $A$}

(a) FORE-LIMB TO FORE-LIMB PATHWAY The shock was applied to the animal using the circuit shown in Figure 5. Measurements were made of the peak values of amplitudes of the first half cycle of the voltage, and of the corresponding peak currents for various voltage settings of the apparatus. The results are given in Table $I$ and illustrated in Figures 6 and 7. Since the voltage and current are similar in waveshape, and are in phase, the impedance of the animal can be considered as a non-reactive resistor of approximately $1,000 \Omega$ (see Fig. 8). Care was taken to minimize the resistances at electrode locations by shaving the hair, by the use of electrodes frequently wetted with saline solution, and by holding the electrodes firmly by rubber bands. Since the internal impedance of the source was about 12 times that of the animal, and as the impedances of different animals do not vary by a wide margin, it can be assumed that the response shown in Table $I$ and associated figures are typical.
D.P. G. OUTPUT

SWITCH 52

Fig. 4. The sequence of operation of switching relays.

OUTPUT OF SOURCE :

SWITCH S1

TABLE I

Experimental Results on Rabbits: Current Pathway, FORE-LIMB TO FORE-LIMB

\begin{tabular}{c|c|c|c}
\hline $\begin{array}{c}\text { Instrument } \\
\text { Setting } \\
(\text { peak } k V)\end{array}$ & $\begin{array}{c}\text { Applied } \\
\text { Voltage } \\
(\text { peak V) }\end{array}$ & $\begin{array}{c}\text { Current } \\
(\text { peak } m A)\end{array}$ & Ratio $E / I(\Omega)$ \\
\hline I & 92 & 102 & 900 \\
2 & 160 & 145 & 1,110 \\
3 & 235 & 217 & 1,080 \\
4 & 320 & 290 & 1,100 \\
5 & 420 & 392 & 1,070 \\
\hline
\end{tabular}

Average animal resistance $I, 040 \Omega(r=0.99)$.

It was not possible to control the waveshape obtained from the apparatus, and Figs 6 and 7 illustrate the extremes. The output was unidirectional at the lower voltages, but an overshoot of the opposite polarity occurred at the higher voltages, the transition occurring at about $300 \mathrm{~mA}$ (peak), corresponding to an apparatus voltage

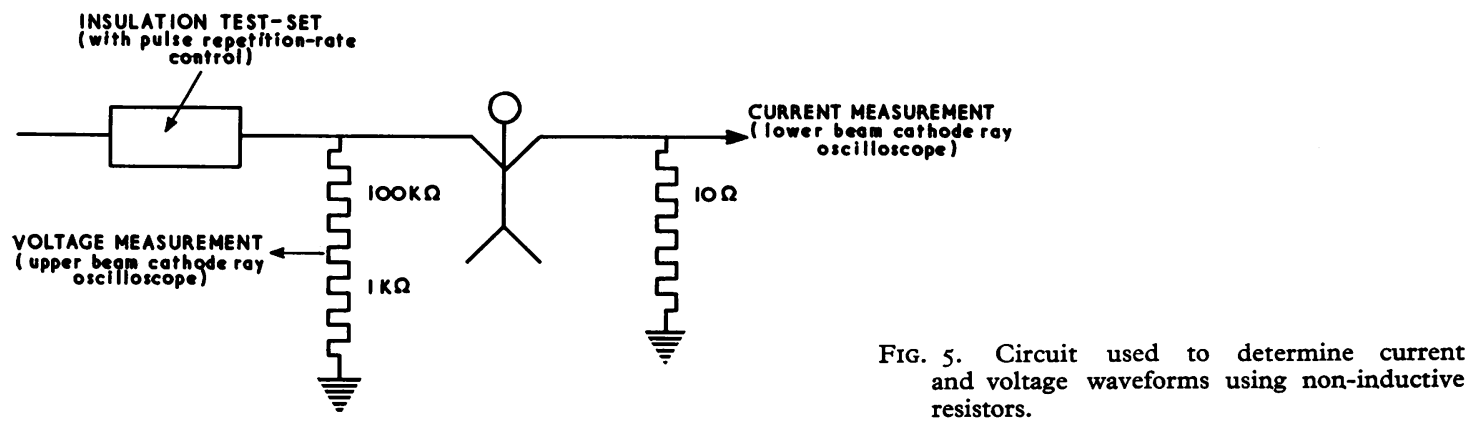




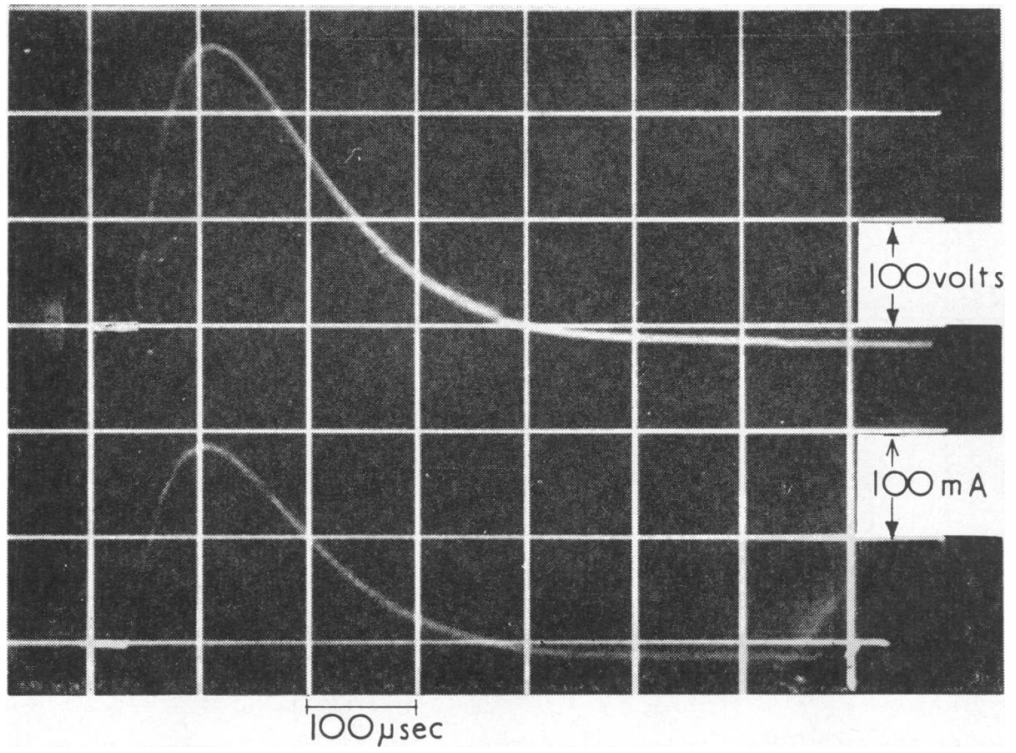

Fig. 6. Voltage and current waveforms from source $A$ at lower voltage settings.

FIG. 7. Current waveform from

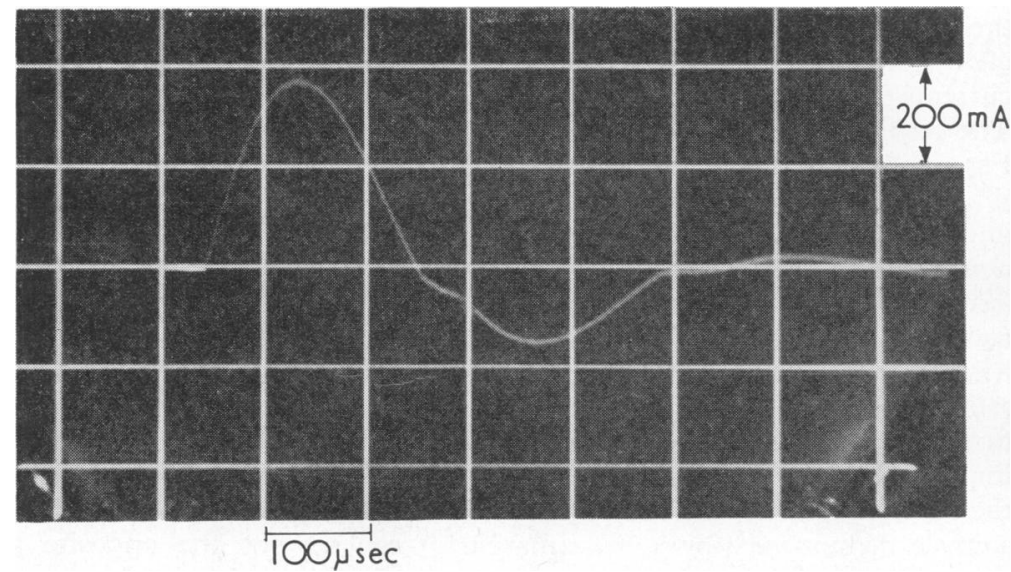
source $A$ at higher voltage settings.

setting of $4 \mathrm{kV}$. All the measurements were taken from the first cycle. The overshoot, when present, was invariably smaller in amplitude and occurred within the absolute refractory period of muscle tissue, and it is believed that the change in waveshape of the output is of small importance so far as this particular investigation is concerned.

Observations of the animals during a series of shocks confirmed the expectation that increasing the rate of pulses would result in clonic contractions becoming more rapid until fusing into tetanic contractions at about 20 to $30 \mathrm{c} / \mathrm{s}$.

At the lower applied voltages the chest muscles were held in tetanic contraction, but diaphragmatic respiration was observed and recorded. This is similar to the finding with $50 \mathrm{c} / \mathrm{s}$ alternating current shocks (Lee and Zoledziowski, 1964). At the highest voltage setting, complete arrest of respiration was observed when the pulse repetition rate was $30 \mathrm{c} / \mathrm{s}$. Results of fore-limb to fore-limb shocks, taking into account these two variables of pulse repetition rate and current, are presented in Table II.

Thus it is seen that at $30 \mathrm{c} / \mathrm{s}$ currents of about 145 peak $\mathrm{mA}$, i.e., apparatus voltage setting $2 \mathrm{kV}$, seriously impaired respiratory movement, permit- 


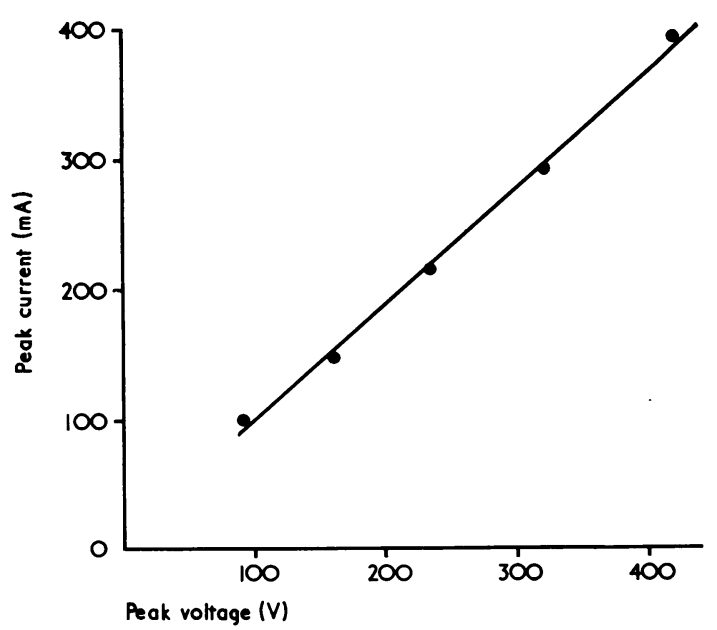

Fig. 8. The relationship of peak current to peak voltage (fore-limb to fore-limb pathway).

TABLE II

EFFECTS ON RESPIRATION OF FORE-LIMB to FORE-LIMB SHOCKS

\begin{tabular}{c|c|c|c|c}
\hline \multirow{3}{*}{$\begin{array}{c}\text { Instrument } \\
\text { Setting }(k V)\end{array}$} & \multicolumn{3}{|c}{ Pulse Repetition Rate $(c / s)$} \\
\cline { 2 - 5 } & 5 & 10 & 20 & 30 \\
\hline I & - & N & N & N \\
2 & - & N & N & D \\
3 & - & N & N & D \\
4 & - & N & D & D \\
5 & N & N & D & A \\
\hline
\end{tabular}

$\mathrm{N}=$ normal respiration; $\mathrm{D}=$ diaphragmatic respiration; $A=$ arrest of respiration.

ting only diaphragmatic respiration to continue, whilst at currents of about $390 \mathrm{~mA}$ (setting $5 \mathrm{kV}$ ) respiration was completely arrested. There was no complete arrest of respiration when the pulse repetition rate was $20 \mathrm{c} / \mathrm{s}$, possibly due to the voltage limitations of the equipment. With pulse repetition rates of $10 \mathrm{c} / \mathrm{s}$ and below, respiration was not impeded, although the rate was sometimes varied, for it was observed, during experiments to determine the effect on the heart, that a pulse repetition rate of about $5 \mathrm{c} / \mathrm{s}$ did not arrest respiration, even at about $390 \mathrm{~mA}$. The shock, in fact, appeared to cause respiratory movements to coincide with each pulse application. (b) FORE-LIMB TO HIND-LIMB PATHWAY The results of measurements of current and voltage using the pathway left fore-limb to right hind-limb are shown in Table III.

The current and voltage waveforms had shapes similar to those obtained with the fore-limb to fore-limb pathway, and were again in phase. Thus the impedance of the animal is essentially a linear resistance having an average value of about I,, $000 \Omega$.

\section{TABLE III}

Experimental Results on Rabbits: Current Pathway, LEFT FORE-LIMB TO RIGHT HIND-LIMB

\begin{tabular}{c|c|c|c}
\hline $\begin{array}{c}\text { Instrument } \\
\text { Setting } \\
(\text { peak kV })\end{array}$ & $\begin{array}{c}\text { Applied } \\
\text { Voltage } \\
(\text { peak V) }\end{array}$ & $\begin{array}{c}\text { Current } \\
(\text { peak } m A)\end{array}$ & Ratio $E / I(\Omega)$ \\
\hline I & 75 & 64 & 1,170 \\
2 & 120 & 140 & 860 \\
3 & 185 & 190 & 975 \\
4 & 230 & 260 & 885 \\
5 & 330 & 330 & 1,000 \\
\hline
\end{tabular}

Average animal resistance $978 \Omega$.

TABLE IV

EFFECTS ON RESPIRATION OF FORE-LIMB TO HIND-LIMB SHOCK

\begin{tabular}{c|ccc}
\hline $\begin{array}{c}\text { Instrument } \\
\text { Setting } \\
(k V)\end{array}$ & \multicolumn{3}{|c}{ Pulse Repetition } \\
\cline { 2 - 4 } & ro Rate $(c / s)$ \\
\hline I & N & No & 30 \\
2 & & D & D \\
3 & N & D & A \\
4 & N & D & \\
5 & D & \\
\hline
\end{tabular}

$\mathrm{N}=$ normal respiration; $\mathbf{D}=$ diaphragmatic respiration; $\mathrm{A}=$ arrest of respiration.

As with fore-limb to fore-limb shocks, the effects depended on the two variables of current and pulse repetition rate and are presented in Table IV.

With a pulse repetition rate of $30 \mathrm{c} / \mathrm{s}$ respiration was arrested by currents of about I40 mA upwards, which corresponded to an applied voltage of about I20 or more peak volts or to an instrument setting of $2 \mathrm{kV}$ upwards. As with fore-limb to fore-limb shocks, respiration started again spontaneously after the shock and without a delay. At a pulse repetition rate of $20 \mathrm{c} / \mathrm{s}$, partial arrest of respiration, 
allowing only diaphragmatic movement, was found with lower currents, beginning at about $140 \mathrm{~mA}$, than with fore-limb to fore-limb shock, when it was not observed until a current of about $290 \mathrm{~mA}$ was reached. With the fore-limb to hind-limb shocks, the diaphragm lies directly in the current pathway, and the effects, therefore, are to be expected at lower current values.

Source $B$ When the high voltage output of the ignition coil is connected directly to the animal, the current waveshape consists of a single pulse comprising a highly damped sinusoidal A.C. component superimposed on an exponentially decaying direct component. Oscillograms illustrating the output voltage and current as the contacts in the primary winding of the ignition coil open are presented in Figure 9. The frequency of the A.C. oscillatory discharge shown in Fig. 9 is approximately $10,000 \mathrm{c} / \mathrm{s}$. The peak currents and waveforms were virtually identical whether a fore-limb to fore-limb or a fore-limb to hind-limb current pathway was used. The A.C. components of voltage and current were similar and in phase, from which it is concluded that the animal impedance may be assumed to be non-reactive.

When the contact breaker controls the ignition coil, the effect produced is a series of current pulses of identical waveform at pulse repetition rates which were varied from eight to 16 per second. The repetition rate is so slow that each transient has completely discharged before the next pulse is produced. The pulse of greatest magnitude is created when the points of the contact breaker open; however, an exponentially decaying direct component of reversed polarity is produced when the contacts close, thereby energizing the ignition coil. The complete pulse thus consists of two main direct components which alternate in polarity, the the first of which may contain a superimposed A.C. oscillatory discharge, while the second pulse consists of a D.C. decaying pulse and no A.C. component, as shown in Figure Io.

(a) FORE-LIMB TO FORE-LIMB PATHWAY Current pulses supplied through the distributor spark gap did not cause arrest of respiration, but each current pulse produced a discrete contraction of the respiratory muscles. In some instances, when the pulse repetition rate was increased to 16 pulses per second, the fore-limbs were observed to be in tetanic contraction, but diaphragmatic respiration continued.

(b) FORE-LIMB TO HIND-LIMB PATHWAY Similar effects were observed when the current was passed from the left fore-limb to the right hind-limb. There was not complete arrest of respiration, even with a pulse repetition rate of $16 \mathrm{c} / \mathrm{s}$.

A pulse repetition rate of 12 per second supplied through the distributor spark gap is equivalent to

TABLE V

EFFECT OF SHock on Heart Rate

\begin{tabular}{c|c|c|c|c|c}
\hline \multirow{2}{*}{$\begin{array}{c}\text { Pulse Repetition } \\
\text { Rate }\end{array}$} & $\begin{array}{c}\text { Peak Current } \\
(m A)\end{array}$ & $\begin{array}{c}\text { Shock Duration } \\
(\text { sec. })\end{array}$ & Before Shock & During Shock & After Shock \\
\cline { 4 - 5 } & &
\end{tabular}

Source $A$ Fore-limb to fore-limb pathway

\begin{tabular}{l|l|l|ccc}
$30 \mathrm{c} / \mathrm{s}$ & 145 & 5 & 240 & 210,250 & 240 \\
$30 \mathrm{c} / \mathrm{s}$ & 217 & 15 & $330-360$ & $240,210,240$ & 330 \\
$30 \mathrm{c} / \mathrm{s}$ & 290 & 10 & 270 & $270,330,360$ & 270 \\
$30 \mathrm{c} / \mathrm{s}$ & 392 & 15 & 240 & $110-130$ & 270,245 \\
\hline
\end{tabular}

Fore-limb to hind-limb pathway

\begin{tabular}{|c|c|c|c|c|c|}
\hline $\begin{array}{l}30 \mathrm{c} / \mathrm{s} \\
30 \mathrm{c} / \mathrm{s} \\
30 \mathrm{c} / \mathrm{s} \\
30 \mathrm{c} / \mathrm{s}\end{array}$ & $\begin{array}{r}64 \\
140 \\
260 \\
330\end{array}$ & $\begin{array}{l}\text { Io } \\
\text { ro } \\
\text { Io } \\
\text { ro }\end{array}$ & $\begin{array}{l}300 \\
330 \\
360 \\
360\end{array}$ & $\begin{array}{c}300-360 \\
217 \\
142 \\
150-120\end{array}$ & $\begin{array}{c}390,360 \\
360 \\
300 \\
240,330,360\end{array}$ \\
\hline
\end{tabular}

Source B Fore-limb to fore-limb pathway

8.5 pulses $/ \mathrm{sec}$. 14.0 pulses $/ \mathrm{sec}$. 16.0 pulses/scc.

\begin{tabular}{l|l|c}
62 & 10 & $315-320$ \\
62 & 10 & 315 \\
62 & 10 & 330
\end{tabular}

300
300
315,330

315,330 

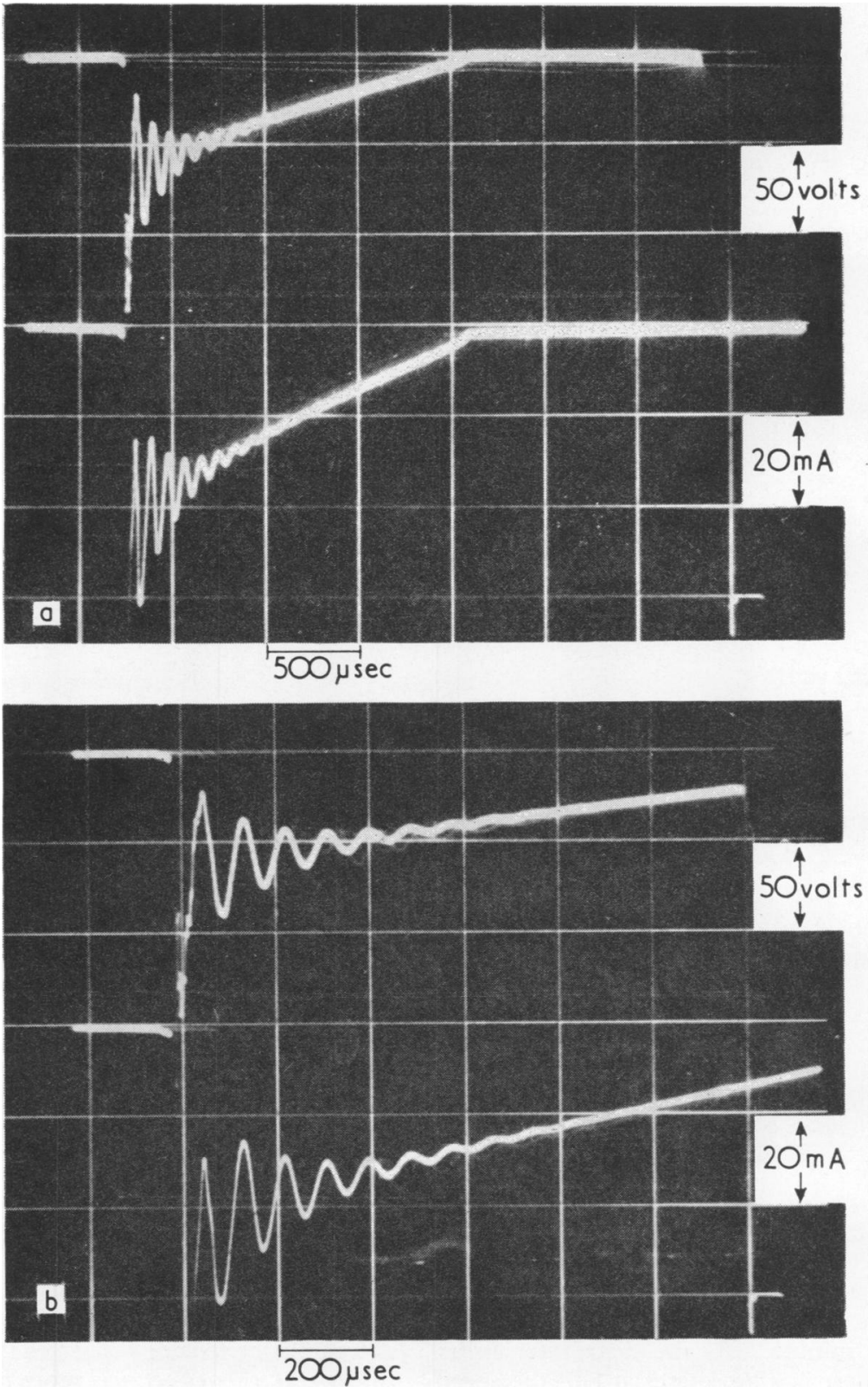

Fig. 9. (a) Voltage and current obtained directly from ignition coil (source B); (b) voltage and current obtained directly from the ignition coil (source B) shown with an expanded time base. 



FIG. Io. (a) The current from source B after passing across the distributor spark gap; (b) voltage and current from source B after passing across distributor spark gap; shown with an expanded time base.

720 pulses per minute. As the distributor in an ordinary motor car engine rotates at half the speed of the crankshaft, this pulse repetition rate corresponds to an engine speed of about $\mathrm{I}, 500 \mathrm{rev} . / \mathrm{min}$.

\section{Effects on the Heart}

Source $A$ In the early experiments, in which the pulses were applied at a fixed rate of 30 per second (that is, not using the circuits illustrated in Fig. 2), it was observed that the pulse rate was slowed during the application of the shock (Table V). In general, this effect was more marked the greater the current. At the end of the shock the heart rate rapidly returned to its pre-shock value.

Although switching circuits designed to deliver pulses on the $T$ wave operated correctly (see Figs IIa and IIC), application of a shock to the animal disturbed the E.C.G. record very considerably. This disturbance is shown in Fig. $\mathrm{Irb}$, and it was found to be caused by the 'noise' due to the electrical potentials accompanying the muscular 

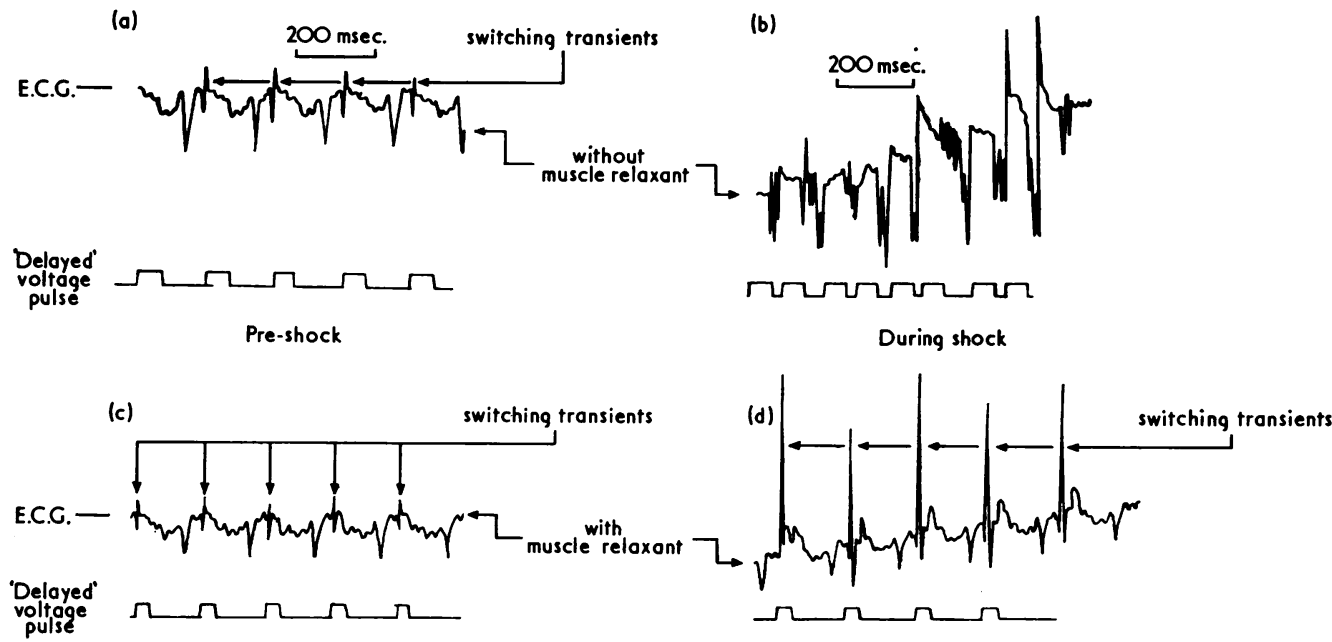

FIG. II. (a) and (c) E.C.G. records showing switching transients before a shock was delivered; (b) E.C.G. record illustrating the interference from muscular contractions during a shock; (d) E.C.G. record during a shock with administration of the muscle relaxant.

contractions of the animal subjected to the shock. This was eliminated by a muscle relaxant, suxamethonium chloride, administered as an intravenous drip, respiration being maintained artificially. Figures IIb and IId show a recording obtained without and with muscle relaxant. The instant of the shock application occurs at the beginning of the switching transient, this corresponding to the upward step of the $50 \mathrm{~V}$ pulse from source $\mathrm{A}$.

Ventricular fibrillation occurs only if the current is passed during the relative refractory period ( $T$ wave) of the ventricular muscle. However, in the present series of experiments we have been concerned with pulses with a width of about $0.3 \mathrm{msec}$. This is much shorter than the $T$ wave. It therefore appeared necessary to study the effects of delivering the pulses at different parts of the $T$ wave, and experiments were designed to deliver the pulses either at the peak of the $T$ wave or about Io msec. either side of this (Fig. I2a-c). Trains of pulses lasting Io seconds were delivered with a voltage applied to the animal of 420 peak volts, and a corresponding current of about $390 \mathrm{~mA}$ peak, at different parts of the $T$ wave. Ventricular fibrillation was not produced in any of these experiments, which were repeated on six different animals.

Source $B$ When the shock was applied from source B (Fig. 3), fibrillation was not produced either with the fore-limb to fore-limb pathway or with the fore-limb to hind-limb pathway. The experiment was repeated on four different animals.

In view of the fact that the current pulse delivered through the distributor had different characteristics from that delivered directly from the secondary coil, it was decided to repeat the above experiment using current pulses from the distributor. It was, therefore, necessary to fix the distributor opposite to a contact point to cause the square pulses from the delayed pulse generator to operate a relay switch


Fig. 12. (a-c) Tracings from oscillograms showing (upper trace) timing of shock pulses and (lower trace) E.C.G. 


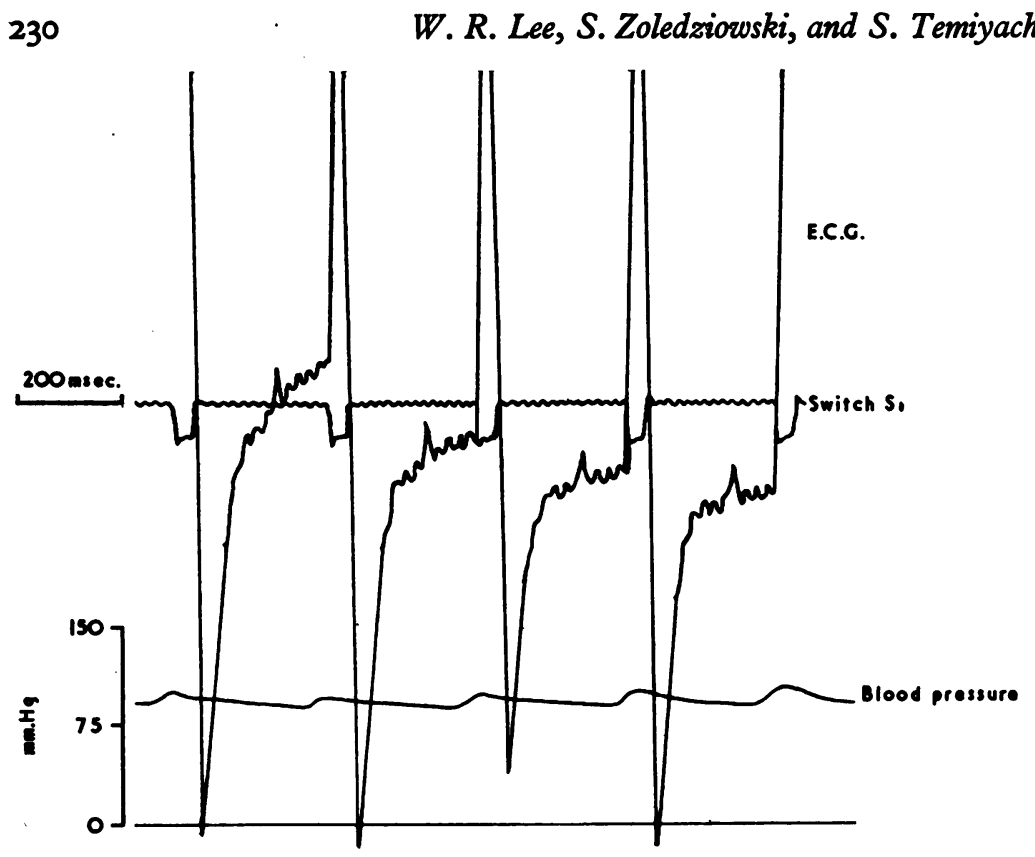

FIG. 13. Tracing from experimental record illustrating successive shocks at a predetermined part of the cardiac cycle. Note the large switching transients.

$S_{2}$ in the primary circuit of the ignition coil. In order to produce a pulse with characteristics similar to that from a rotating distributor, a $0.5 \mu \mathrm{F}$ capacitor was connected across the contact points of the relay $S_{2}$. The waveshape produced by this system had a close resemblance to that produced when the contact breaker was rotating and the current output was obtained through the distributor spark gap. The equation for positive values of $i$ is:

$$
\mathrm{i}=0.038\left[\mathrm{I}-\mathrm{e}^{-\frac{\mathrm{t}}{0.0004}} \cdot \cos (2 . \pi 8,800)\right]-28.3 \mathrm{t}
$$

where $i$ is the current in amperes and $t$ is the time in seconds.

Using the circuit of Fig. 3, it was possible to pass current pulses from the distributor and time them to coincide with the relative refractory period- $T$ wave (Fig. 13). Ventricular fibrillation was not produced with either the fore-limb to fore-limb or the forelimb to hind-limb pathway.

It will also be observed from Table $V$ that shocks from source $B$ do not affect the pulse rate. It will be noted that the current output of source $B$ is smaller than the current output of source $A$, and no effect on the pulse rate was observed if the fore-limb to fore-limb peak current from source $A$ was below $140 \mathrm{~mA}$.

\section{Discussion}

Effects on Respiration The insulation test-set (source A) may be adjusted to deliver pulses at different voltages with a maximum pulse repetition rate of about 30 per second. Variations in both these factors were investigated.

At low pulse repetition rates of about 5 and 10 per second each pulse caused a discrete contraction, and it was not until the pulse repetition rate was raised above 20 per second that these contractions fused to produce tetanic contraction with arrest of respiration.

With fore-limb to fore-limb shocks at 30 pulses per second, peak currents of about $100 \mathrm{~mA}$ did not produce respiratory arrest by tetanic contraction; complete arrest of respiration was not produced until the current reached about $392 \mathrm{~mA}$. Under practically identical experimental conditions, using urethane as an anaesthetic, this threshold, of respiratory arrest from tetanic contraction, was about $50 \mathrm{~mA}$ ( $70 \mathrm{~mA}$ peak value) for 50 cycles per second alternating currents (mains frequency) and about $350 \mathrm{~mA}$ for direct currents (Angelis, Lee, and Zoledziowski, 1966).

The motor-car ignition system delivers a virtually fixed output voltage, and only the frequency of the pulses varies with engine speed. These pulses, having a peak current of $72 \mathrm{~mA}$ under 
the experimental conditions, in which contact resistance is reduced to a minimum, are capable of causing muscular contraction of the thorax of the experimental animal, and, if they are sufficiently frequent (approximately I6 per second and more), the contractions fuse to produce tetanic contraction of the limbs but no arrest of respiration. In comparison, as already noted, under the same experimental conditions, tetanic contraction of the respiratory muscles is produced by a $50 \mathrm{c} / \mathrm{s}$ alternating current of about the same peak current value ( $50 \mathrm{~mA}$ r.m.s. has a peak of $50 \sqrt{2}=70 \mathrm{~mA}$ ).

Another interesting finding with both sources was that the current and voltage waveforms were similar and in phase. Furthermore, with source A increase in current was directly related to increase in applied voltage. These findings suggest that, under these experimental conditions with minimum contact resistance, the animal impedance is resistive with no significant reactanice.

Effects on the Heart It has been shown in dogs, by direct stimulation of the ventricle by Io msec. square wave pulses, that the ventricular fibrillation threshold was lower when three to four cardiac cycles separated successive stimuli than when Io to 15 cycles separated them (van Tyn and MacLean, I96I). If a $60 \mathrm{c} / \mathrm{s}$ current is passed from fore-limb to fore-limb, the threshold of current at which ventricular fibrillation occurs is lowered if the shock embraces several cardiac cycles (shock duration of $I$ to $5 \mathrm{sec}$.) than if it covers only one cardiac cycle (Kouwenhoven et al., 1959). In the present series of experiments conditions were deliberately designed to simulate the worst circumstances by delivering successive shocks during successive ventricular refractory periods ( $T$ waves). Ventricular fibrillation was never produced with either source, even when working at maximum output. Although spontaneous defibrillation is common in the rabbit, even a short period of fibrillation would have been observed as the E.C.G. trace returned within $100 \mathrm{msec}$. of each pulse.

With source $A$ it was not possible to produce ventricular fibrillation with current pulses having peak values of nearly $400 \mathrm{~mA}$. The body impedance was about $\mathrm{I}, 000 \Omega$ and the animal presents a resistance to these pulses. Even if, in accidental circumstances, the skin resistance were to break down, giving a body resistance of only $500 \Omega$, the maximum amplitude of the current pulse would not be expected to increase appreciably because of the high impedance of the source.
These findings may be compared with those using $50 \mathrm{c} / \mathrm{s}$ alternating current and direct currents under similar experimental conditions (except that pentobarbital was the anaesthetic then used). The lowest alternating current found to produce ventricular fibrillation was $71 \mathrm{~mA}$ (Lee and Zoledziowski, 1964) and the lowest direct current observed to produce this effect was about $425 \mathrm{~mA}$ (Angelis et al., 1965).

Thus if the shock is applied from an instrument of similar voltage to source $A$ and of a similar internal impedance, but having a $50 \mathrm{c} / \mathrm{s}$ alternating frequency, death could possibly result either from asphyxia or from ventricular fibrillation. The introduction of a pulsed source and decreasing the repetition frequency of these pulses eliminated both of these dangers in rabbits. Presumably these dangers are also similarly largely decreased for humans.

This work was made possible by grants from the Medical Research Council and the Central Electricity Generating Board. We should like to acknowledge with thanks the loan of apparatus from Rank Bush Murphy Limited, Joseph Lucas Limited, and Chloride Electric Storage Company Limited.

We are very grateful to Professor C. F. Dalziel for reading through the manuscript of this paper and making valuable comments.

Mr. C. L. Tomlin has provided invaluable technical assistance and support throughout this work.

\section{REFERENCES}

Angelis, A. L., Lee, W. R., and Zoledziowski, S. (1965). Brit. F. industr. Med., 22, 210.

,- and - (1966). Proc. int. congr. Occup. Hlth, Vienna, Vol. 5, pp. 247-250.

Dalziel, C. F., Ogden, E., and Abbott, C. E. (1943). Trans. Amer. Inst. elect. Engrs (Elect. Engng.), 62, 745.

Ferris, L. P., King, B. G., Spence, P. W., and Williams, H. B. (1936). Ibid., 55, 498.

Green, J. H., and Howell, J. B. L. (1955). F. Physiol. (Lond.), 130, 33P.

Kouwenhoven, W. B., Chesnut, R. W., Knickerbocker, G. G., Milnor, W. R., and Sass, D. J. (1959). Trans. Amer. Inst. elect. Engrs (Communications and Electronics), Part I: 1959-60, 78, I63.

Lee, W. R. (1965a). Brit. med.F., 2, 616.

(1965b). Med. Sci. Law, 5, 23.

- and Zoledziowski, S. (1964). Brit. F. industr. Med., 21, 135 .

Maclachlan, W. (1930). F. indistr. Hyg., 12, 291.

Morikawa, S., and Steichen, F. (1960). Anesthesiology, $21,222$.

Prevost, J.-L., and Battelli, F. (1899). J. Physiol. Path. I, 1085 .

van Tyn, R. A., and MacLean, L. D. (I96r). Amer. F. Physiol., 201, 457.

Wégria, R., and Wiggers, C. J. (I940). Ibid., 131, 119. 